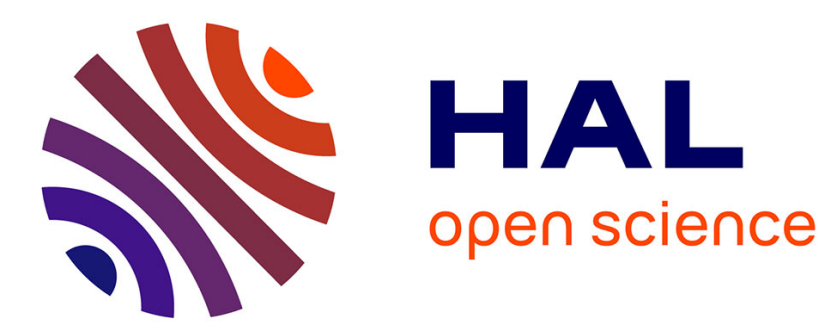

\title{
Mucoceles of the anterior ventral surface of the tongue and the glands of Blandin-Nuhn: 5 cases
}

Nicolas Graillon, Caroline Mage, Marc-Kevin Le Roux, Ugo Scemama, Cyrille Chossegros, Jean-Marc Foletti

\section{- To cite this version:}

Nicolas Graillon, Caroline Mage, Marc-Kevin Le Roux, Ugo Scemama, Cyrille Chossegros, et al.. Mucoceles of the anterior ventral surface of the tongue and the glands of Blandin-Nuhn: 5 cases. Journal of Stomatology, Oral and Maxillofacial Surgery, 2019, 120 (6), pp.509-512. 10.1016/j.jormas.2019.04.005 . hal-03253663

\section{HAL Id: hal-03253663 https://hal.science/hal-03253663}

Submitted on 8 Jun 2021

HAL is a multi-disciplinary open access archive for the deposit and dissemination of scientific research documents, whether they are published or not. The documents may come from teaching and research institutions in France or abroad, or from public or private research centers.
L'archive ouverte pluridisciplinaire HAL, est destinée au dépôt et à la diffusion de documents scientifiques de niveau recherche, publiés ou non, émanant des établissements d'enseignement et de recherche français ou étrangers, des laboratoires publics ou privés. 
Mucoceles of the anterior ventral surface of the tongue and the glands of Blandin Nuhn: 5 cases

N. Graillon ${ }^{1}$, C. Mage ${ }^{2}$, MK Le Roux ${ }^{3}$, U Scemama ${ }^{4}$, C. Chossegros ${ }^{3}$, JM Foletti $^{1}$

1. Aix Marseille Univ, APHM, IFSTTAR, LBA, CHU Conception, Department of Oral and Maxillofacial Surgery, Marseille, France

2. University of Bordeaux, CHU Bordeaux, Pellegrin Hospital, Department of Oral and Maxillofacial Surgery, Bordeaux, France

3. Aix Marseille Univ, APHM, CHU Conception, Department of Oral and Maxillofacial Surgery le, Marseille, France

4. Aix Marseille Univ, APHM, Imaging department, North university hospital, Marseille, France.

\section{Author Contact:}

Nicolas Graillon, MD

Secrétariat de Chirurgie Maxillo-faciale

CHU Conception

147 boulevard baille 13005 Marseille

nicolas.graillon@ap-hm.fr 


\section{Introduction}

Oral mucoceles (MC) are cystic diseases of the oral mucosa [1]. The most common are ranula and MC of the lower lip [2]. Blandin and Nuhn mucoceles (BNMC), which develop at the ventral side of the tongue, are rare benign lesions [2]. They are often misdiagnosed and confused with MC of the floor of the mouth that extend to the ventral surface of the tongue. Their management with marsupialisation is not recommended. The objective of this study was to describe our cases and compare their clinical aspects, check-up, and management with those found in the literature.

\section{Patients and methods}

Five patients, 4 male and one female, were treated for Blandin and Nuhn mucoceles in our department from 2011 to 2017 . The age range was from 7 to 39 years, with an average age of 18.2 years. Four lesions presented as a submucosal swelling, the other one appeared papillary. All the lesions were located at the ventral surface of the tongue near the lingual frenulum. One lesion was medial and 4 were on the left side of the frenulum. One patient underwent an incomplete excision of the lesion performed in other hospital.

\section{Results}

We describe five clinical cases to detail their clinical history, care, and treatment. This study was conducted in accordance with the principles of the Helsinki Declaration (2013)

\section{Case 1 (Fig. 1)}

An 8-year-old male presented with a small lesion of the ventral face of his tongue. Due to the small size and lack of suspect criteria, no further imaging was performed. BNMC was completely removed under local anaesthesia with no complications. The patient was followed during two years without BNMC recurrence. 


\section{Case 2 (Fig. 2 and 3)}

A 16-year-old male presented with a ventral tongue lesion gradually increasing in volume. Preoperative ultrasound and CT showed a unilocular $20 \times 9 \times 9 \mathrm{~mm}$ round avascular cyst with a large axial axis. MRI showed a cystic formation on the left anterior pelvic surface of the tongue in intermediate signal T1 and hypersignal T2. The cyst measured $19 \mathrm{~mm}$ wide, $9 \mathrm{~mm}$ in height, and $7.5 \mathrm{~mm}$ across. There was no gadolinium enhancement.

The lesion was surgically removed under general anaesthesia. The pathological results showed a cystic formation $22 \times 10 \times 10 \mathrm{~mm}$ with foamy histiocytes and mucoid material accumulation. On the outskirts, the corium was the seat of collagen and fibro-inflammatory changes. On the surface, there was a mature squamous, no disorganisation of the epithelial architecture, and no signs of malignancy. The histological appearance favoured a mucoid cyst. The patient was followed during one years without BNMC recurrence.

\section{Case 3 (Fig. 4)}

A 39-year-old male presented with a centimetric ventral tongue lesion. A CT showed a cystic lesion with liquid density. Surgical excision of the BN gland was done under general anaesthesia. The patient was followed during six months without BNMC recurrence.

\section{Case 4 (Fig. 5)}

A 21-year-old male presented with a swelling of the left ventral surface of his tongue. The lesion was indurated and close to the oral floor. Marsupialisation of the sublingual gland and its excision one month later failed. BNMC was initially confused with a ranula, explaining the lack of imaging and the sublingual surgery failure. After excision of the Blandin and Nuhn gland, the patient presented with one recurrence of the mucocele that was treated by a second surgical resection. The patient was then followed during 6 months without recurrence.

\section{Case 5 (Fig. 6)}


A 7-year-old girl presented with a lesion on the left ventral surface of her tongue. Puncture of the lesion was attempted but failed. She underwent a surgical resection without complications. The patient was then followed during 1 year without recurrence

\section{Discussion}

Blandin and Nuhn mucoceles must be understood and recognised to propose complete excision of the Blandin and Nuhn gland and avoid recurrence. BNMC are not very wellknown even if they are more common than suspected [1]. BN glands open in the oral cavity by five to seven small ducts laterally to the lingual frenulum; each gland is $8 \mathrm{~mm}$ wide and 12 to $25 \mathrm{~mm}$ deep [3]. Despite the small size of the BN glands, BNMC can sometimes be large, with a long axis measuring over $5 \mathrm{~cm}$, even in children. In such cases, BNMC can cause suffocation [4] or dysphagia. BNMC are more common in female children [3]; but in the current study there were 4 males and 1 female. Their clinical appearance is unique, with longitudinal swelling in the ventral surface of the tongue parallel to the lingual frenulum. Paraclinical exams (ultrasound, CT, MRI, or needle aspiration) can confirm the diagnosis but are not always necessary, as the diagnosis is clinically obvious. The $\mathrm{BN}$ glands of the affected side must be completely removed (Fig. 7). This requires a longitudinal incision parallel to the frenulum and $5 \mathrm{~mm}$ away from it. After the injection of saline solution with epinephrine, submucosal dissection removes the $\mathrm{BN}$ glands on the affected side $[2,5,6]$, preserving the lingual nerve, the lingual veins, and the Wharton duct. The sublingual gland that is not concerned must be respected.

The most frequent location of MC is at the lower lip (77.9\%), followed by the floor of the mouth and tongue (15.6\%) [2]. BNMC are rare (9.9\% of all oral mucoceles in the Jinbu study [7] and $15.4 \%$ in the de Camargo Moraes study [8]). Generally, these lesions are benign and small, measuring less than $20 \mathrm{~mm}$ in diameter. Because of their clinical characteristics and 
location, these lesions can be confused with vascular lesions, botriomycomes, and squamous papillomas, among others [2,3]. The differential diagnosis of mucoceles is mucoepidermoid carcinoma, whose clinical appearance is similar. It is therefore important to assess the location of the lesion, the presence of trauma, any rapid changes, an increase or decrease in the lesion size, a bluish colour, and fluid consistency.

There are 2 types of lingual mucoceles:

-An exudative form, with the presence of granulation tissue containing leukocytes and phagocytes without epithelial lining of the lesion

-A cystic form, with a cavity lined with a squamous epithelium with inflammatory cells and mucus acini [3]

The cystic form (CF) is more alarming because it can be suffocating while the $\mathrm{CF}$ evolves over several weeks (one week to 6 months) [4]. The CF appears bluish, non-ulcerated, and is painless. The average age is 20 years [7,8], with a female predominance [7].

In the exudative form, we often find a trauma history, which causes a transection of the duct and therefore mucus leakage in the connective tissues. The mucus then causes inflammation and granulation tissue. The retentive cystic form occurs when debris, stones, or inflammation block the duct, causing lesion expansion. Out of 400 cases, Harrison showed that the exudative form affected mostly young subjects (20-30 years of age) at the lower lip while the cystic form instead affected the elderly and in locations other than the lower lip [5].

The recommended treatment is a complete en bloc surgical excision of the lesion [2], even in asymptomatic patients, to prevent increasing volume and complications. Surgery can be performed under local anesthesia (case 1) if the patient is compliant and if the lesion is small [1,6]; in other cases, general anesthesia is necessary (cases 2, 3, 4, and 5) [2]. A vertical incision is made in the ventral surface of the tongue, and the mucus is discharged. Because of 
the presence of adhesion due to inflammation, the lesion walls can be difficult to decease; this can explain the recurrence in some cases (case 4 in the present series). The only patient herein who presented a recurrence was initially treated by marsupialisation and then sublingual gland excision. In this inflammatory context, complete resection of the cystic membrane is difficult and can explain a new recurrence. Some clinicians inject a mixture of alginate into the lesion to better discern the lesion walls once the content has been evacuated. The ventral surface of the tongue is then sutured with absorbable 4.0 stiches [6]. A histological analysis of the excised lesion is performed. The histological analysis is systematic. It shows a wellcircumscribed lesion on top of mucous filled with a colourless mucoid material containing proteins and large histiocytes [4,6].

The postoperative time is often uneventful. Other treatments have been described for large lesions: IV injection of corticosteroids, cryotherapy, laser, "micromarsupialisation," and intralesional steroid injection [4,6]. In his study [9], Zhang treated BN mucoceles by absolute ethanol injection under local anesthesia in 14 patients. Mucoceles disappeared in all patients after 1 to 3 injections. There were no complication. The recurrence was not observed during a 2 years follow-up. The management of Blandin and Nuhn mucoceles is unclear because they are rare and poorly understood. There is no spontaneous regression of the $\mathrm{MC}$, and the common treatment is surgical and performed under local or general anaesthesia. Studies are needed to elucidate the success or failure rates of these treatments before the management of BNMC can be standardised.

\section{Disclosure of interest}

The author declares that he has no disclosure. 


\section{References}

[1] Baurmash HD. Mucoceles and ranulas. J Oral Maxillofac Surg Off J Am Assoc Oral Maxillofac Surg 2003;61:369-78. doi:10.1053/joms.2003.50074.

[2] Garcia Leon N, Marrugo Pardo GE. Mucocele of the glands of Blandin-Nuhn: a case report. Colomb Medica Cali Colomb 2013;44:46-7.

[3] Adachi P, Soubhia AMP, Horikawa FK, Shinohara EH. Mucocele of the glands of Blandin-Nuhn--clinical, pathological, and therapeutical aspects. Oral Maxillofac Surg 2011;15:11-3. doi:10.1007/s10006-010-0221-1.

[4] Andiran N, Sarikayalar F, Unal OF null, Baydar DE, Ozaydin E. Mucocele of the anterior lingual salivary glands: from extravasation to an alarming mass with a benign course. Int J Pediatr Otorhinolaryngol 2001;61:143-7.

[5] Harrison JD. Salivary mucoceles. Oral Surg Oral Med Oral Pathol 1975;39:268-78.

[6] Kumaresan R, Karthikeyan P, Mohammed F, Thapasum Fairozekhan A. A novel technique for the management of blandin-nuhn mucocele: a case report. Int J Clin Pediatr Dent 2013;6:201-4. doi:10.5005/jp-journals-10005-1219.

[7] Jinbu Y, Kusama M, Itoh H, Matsumoto K, Wang J, Noguchi T. Mucocele of the glands of Blandin-Nuhn: clinical and histopathologic analysis of 26 cases. Oral Surg Oral Med Oral Pathol Oral Radiol Endod 2003;95:467-70. doi:10.1067/moe.2003.51.

[8] de Camargo Moraes P, Bönecker M, Furuse C, Thomaz LA, Teixeira RG, de Araújo VC. Mucocele of the gland of Blandin-Nuhn: histological and clinical findings. Clin Oral Investig 2009;13:351-3. doi:10.1007/s00784-009-0252-x.

[9] Zhang J, Wang C. The Application of Absolute Ethanol in the Treatment of Mucocele of the Glands of Blandin-Nuhn. J Craniofac Surg 2016;27:e641-2.

doi:10.1097/SCS.0000000000002993. 


\section{Figures}

Figure 1: Small Blandin and Nuhn mucocele in an 8 years old child (case 1)

Figure 2: Left Blandin and Nuhn mucocele in a 16 years old male, progressive volume increase (case 2)

Figure 3: Multimodal imaging of mucocele of the glands of Blandin-Nuhn (case 2)

$\mathrm{a}, \mathrm{b}, \mathrm{d}, \mathrm{d}$ : MRI sequences, respectively axial T2SE with suppression of fat, coronal T2SE, axial T1SE and post gadolinium coronal T1SE ; e: contrast-enhanced CT; f: ultrasound.

Ultrasound and contrast enhanced CT show an oblong cyst (arrow heads) situated on the left anterior ventral surface of the tongue, with liquid density but not strictly anechogenic. MRI confirms the liquid content of this cyst (low T1signal, high T2signal and no postcontrast enhanced) with a thin wall enhancement.

Figure 4: Left Blandin and Nuhn mucocele in a 39 years old male (case 3)

Figure 5: Left Blandin and Nuhn mucocele (red arrow) previously confused with a ranula and first treated by sublingual excision (case 4)

Figure 6: Left Blandin and Nuhn mucocele in a 7 years old female after cyst puncture failure (case 5).

Figure 7: Left Blandin and Nuhn excision after a longitudinal incision parallel to the frenulum and dissection respecting lingual nerve and sublingual gland (case 4). 


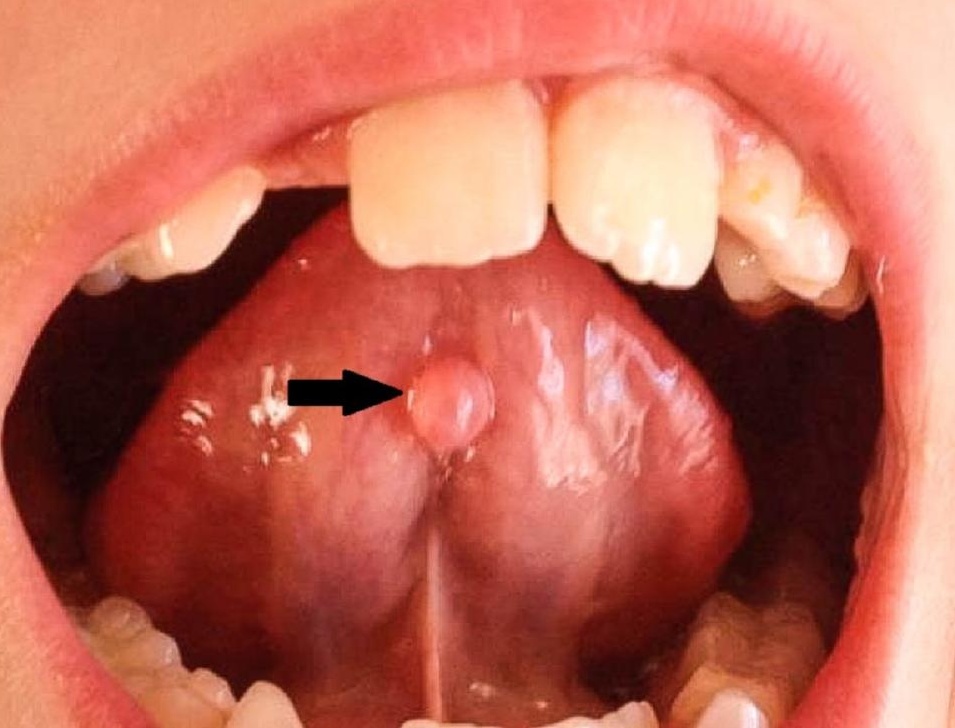




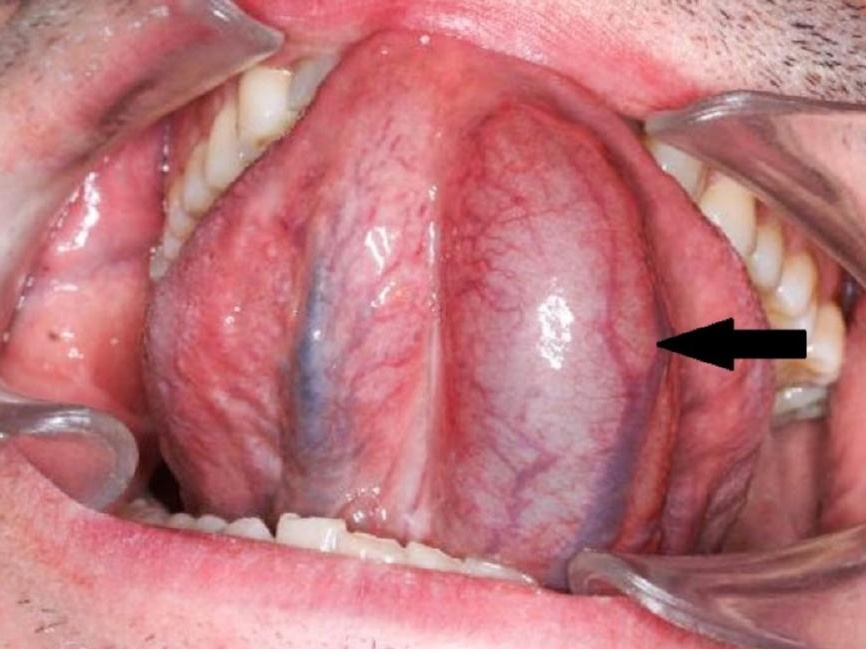




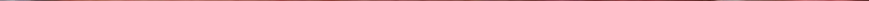




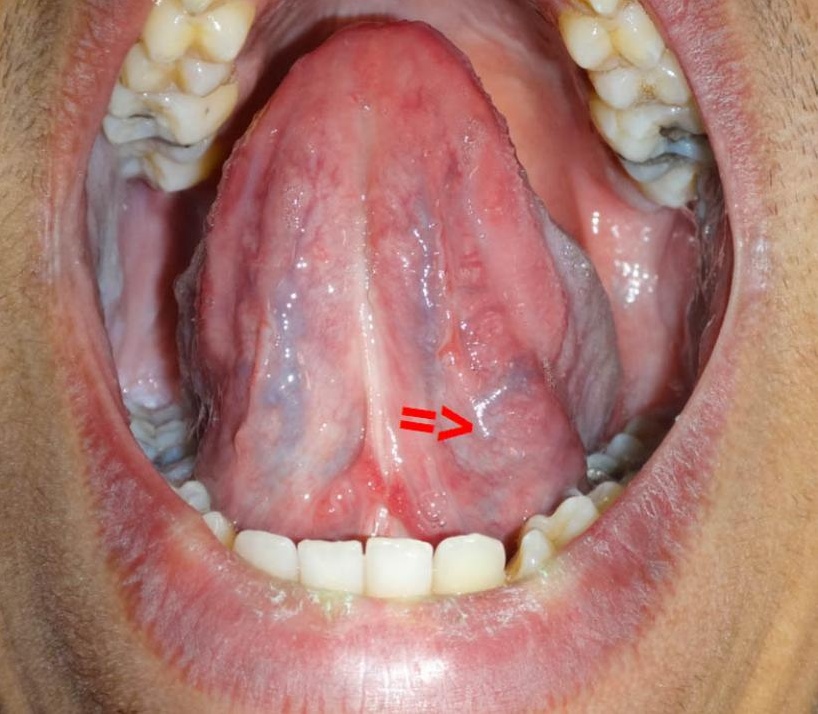




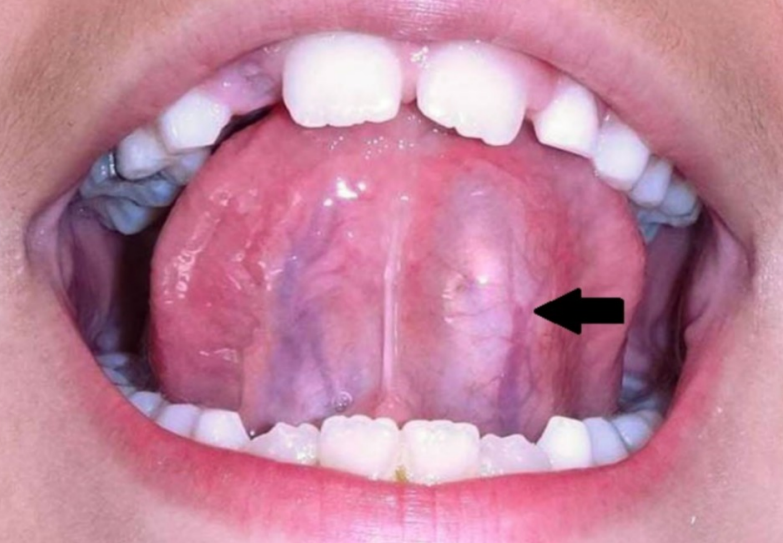




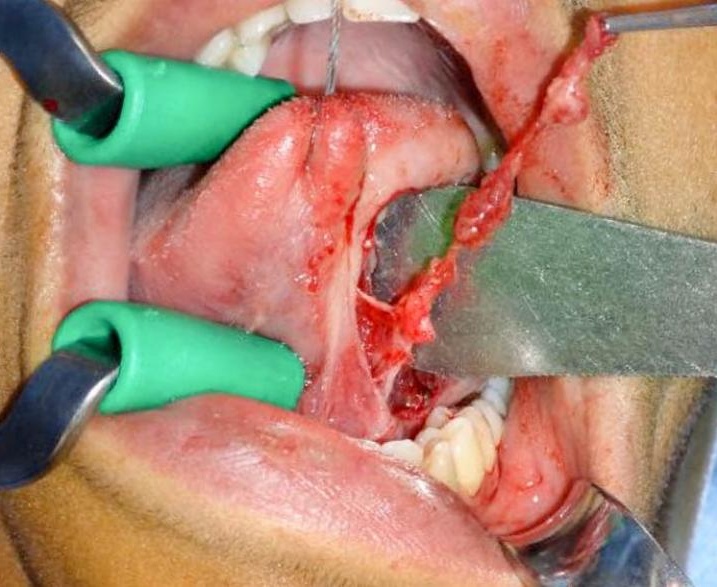

